\title{
High rate of core promoter and precore mutations in patients with chronic hepatitis B
}

\author{
Sumbella F. Baqai · James Proudfoot • \\ Debbie H. Yi • Michael Mangahas • \\ Robert G. Gish
}

Received: 21 June 2014/Accepted: 3 December 2014/Published online: 25 December 2014

(C) The Author(s) 2014. This article is published with open access at Springerlink.com

\begin{abstract}
Background The prevalence of precore (PC) and core promoter $(\mathrm{CP})$ mutations in patients with chronic hepatitis $\mathrm{B}$ virus (HBV) infection (CHB) and their impact on liver disease is incompletely defined in the United States.

Methods A retrospective chart review using a cross-sectional approach of $1,186 \mathrm{CHB}$ patients was conducted.

Results Of 926 patients tested for $\mathrm{HBV}$ e antigen (HBeAg), $37 \%$ were $\mathrm{HBeAg}+$. Of 194 patients tested for mutations, $80 \%$ had PC or CP mutations or both; $89 \%$ of HBeAg-negative and $56 \%$ of $\mathrm{HBeAg}+$ patients had PC or $\mathrm{CP}$ mutations or both $(p<0.001)$. The mean $\log _{10}$ ALT
\end{abstract}

S. F. Baqai

Department of Internal Medicine, Alameda County Medical

Center, 1411 E. 31st St., Oakland, CA 94602-1018, USA

e-mail: sumbella@gmail.com

J. Proudfoot

Biostatistics Unit, Clinical and Translational Research Institute,

University of California, San Diego, 9500 Gilman Drive,

La Jolla, CA 92093, USA

e-mail: jproudfoot@ucsd.edu

D. H. Yi

Emergency Medicine and Neurocritical Care, Hospital of the University of Pennsylvania, 3400 Spruce St, Philadelphia, PA 19104, USA

e-mail: Debbie.Yi@uphs.upenn.edu

\section{Mangahas}

University of California, San Francisco/University of California, Berkeley, Joint Medical Program, University of California, San Francisco, School of Medicine, 513 Parnassus Avenue,

San Francisco, CA 94143, USA

e-mail: mmangahas@gmail.com

R. G. Gish

Robert G. Gish Consultants, LLC, 6022 La Jolla Mesa Drive, San Diego, CA 92037, USA was significantly lower in patients with both mutations compared to patients without mutations. The mean $\log _{10}$ HBV DNA was significantly lower in patients with only PC mutations (4.82) compared to patients without mutations (5.71, $p=0.019)$. With the study population divided into four subgroups based on ALT level at time of diagnosis, cirrhosis incidence was significantly higher in patients with ALT $1-2 \times$ ULN and ALT $>2 \times$ ULN compared to patients with ALT $\leq 0.5 \times$ ULN.

Conclusions Our finding that PC and CP mutations may be associated with milder liver disease in some patients could serve as the basis for longitudinal studies to help

\section{R. G. Gish}

Department of Medicine, Division of Gastroenterology and Hepatology, Stanford University, 291 Campus Drive, Stanford, CA 94305, USA

R. G. Gish

Hepatitis B Foundation, 3805 Old Easton Rd, Doylestown, PA 18902, USA

R. G. Gish

St. Joseph's Hospital and Medical Center, 350 W Thomas Road, Phoenix, AZ 85013, USA

R. G. Gish

Department of Clinical Medicine, University of Nevada School of Medicine, 2040 West Charleston Boulevard, Las Vegas,

NV 89102, USA

R. G. Gish ( $₫)$

Hepatitis B Foundation, 6022 La Jolla Mesa Drive, San Diego, CA 92037, USA

e-mail: rgish@ robertgish.com 
delineate treatment need and duration in patients with these mutations. If confirmed, the finding of an association between ALT 1-2 $\times$ ULN and increased incidence of cirrhosis could call into question guidelines which only recommend treatment with $\mathrm{ALT}>2 \times \mathrm{ULN}$.

Keywords Chronic hepatitis B - Precore mutations - Core promoter mutations - HBeAg-positive $\cdot \mathrm{HBeAg}$-negative ALT

$\begin{array}{ll}\text { Abbreviations } \\ \text { CHB } & \text { Chronic hepatitis B } \\ \text { HBeAg } & \text { Hepatitis B e antigen } \\ \text { CP } & \text { Core promoter mutation } \\ \text { PC } & \text { Precore mutation } \\ \text { HBV } & \text { Hepatitis B virus } \\ \text { anti-HBe } & \text { Hepatitis B e antibody } \\ \text { HCC } & \text { Hepatocellular carcinoma } \\ \text { HBsAg } & \text { Hepatitis B surface antigen } \\ \text { Anti-HBc } & \text { Hepatitis B core antibody } \\ \text { IgG } & \text { Immunoglobulin G } \\ \text { CPMC } & \text { California Pacific Medical Center } \\ \text { HCV } & \text { Hepatitis C virus } \\ \text { HDV } & \text { Delta hepatitis virus } \\ \text { HIV } & \text { Human immunodeficiency virus } \\ \text { AFP } & \text { Alpha-fetoprotein } \\ \text { AASLD } & \text { American Association for the Study of Liver } \\ & \text { Diseases } \\ \text { EASL } & \text { European Association for the Study of the } \\ & \text { Liver } \\ \text { APASL } & \text { Asian Pacific Association for the Study of the } \\ & \text { Liver }\end{array}$

\section{Introduction}

Chronic hepatitis B (CHB) patients with hepatitis B e antigen-negative (HBeAg-negative) disease often have mutations in the core promoter (CP) and precore (PC) regions of hepatitis $\mathrm{B}$ virus (HBV) that explain the decreased $\mathrm{HBeAg}$ production [1]. Many $\mathrm{HBeAg}$-positive patients have infection that includes both wild-type virus and variants with $\mathrm{CP}$ mutations [2, 3] and, less commonly, PC mutations [2, 4]. In patients with ongoing viral replication, seroconversion, $\mathrm{HBeAg}$ loss, and development of the hepatitis B e antibody (anti-HBe) are often associated with emergence and selection of replication-competent virions with $\mathrm{PC}$ mutations [3]. In $\mathrm{HBeAg}+$ patients the progression toward an "eAg-negative" disease may begin with $\mathrm{CP}$ mutations (and, to a lesser extent, PC mutations) well before the date of ultimate $\mathrm{HBeAg}$ loss.
A 2003 US study reported that the prevalence of PC and $\mathrm{CP}$ variants was much more common in $\mathrm{HBeAg-negative}$ than in $\mathrm{HBeAg}$-positive patients (PC, 38 vs. $9 \%$; CP, 51 vs. $36 \%$ ) but inclusion of only treatment-naïve patients may have resulted in prevalence underestimation [4]. A 2013 US study of $\mathrm{HBeAg}+$ patients reported a prevalence of $28 \%$ (PC mutations) and $17 \%$ (CP mutations); however, the patient population was almost entirely $(92.3 \%)$ Asian Americans with genotypes B and C [5]. Thus, the baseline US prevalence of PC and CP mutants in community settings that include both treatment-naïve and -experienced patients from all ethnic backgrounds remains undefined.

There is conflicting data on the effect of PC and CP variants on the risk of serious liver disease. Multiple studies have reported an association between CP mutations and increased liver inflammation [6, 7], cirrhosis [8] and hepatocellular carcinoma (HCC) [8-13]. Some researchers have reported an association between PC mutations and fulminant hepatitis [14, 15], while others found either no such association [16] or, in fact, an association with decreased inflammation [6]. One study reported an association between PC variant G1896A and a decreased risk of HCC [13]. Furthermore, various studies have reported (1) no correlation between PC/CP mutations and HBV DNA levels [17], (2) an association between most CP and PC mutations with significantly reduced viral replication [18], (3) an association between up-regulation of viral replication with CP mutations other than those at 1762/1764 [19], and (4) an association between increased viral replication and the PC mutation [20].

We describe here a large cross-sectional study of both $\mathrm{HBeAg}+$ and $\mathrm{HBeAg}-$ negative $\mathrm{CHB}$ patients from community settings, including patients from all ethnic backgrounds, in which we evaluated the presence of PC and $\mathrm{CP}$ mutations (with separate analyses of treatmentnaïve and -experienced patients), and the possible association of these mutations with ALT levels, HBV DNA, prevalence of cirrhosis and incidence of HCC. We also assessed the association of various levels of ALT at the time of diagnosis with the incidence of cirrhosis and HCC.

\section{Methods}

A total of 1,186 CHB patients who had undergone longterm follow up in 14 liver clinics in California and Nevada linked to California Pacific Medical Center (CPMC) were retrospectively analyzed using a cross-sectional approach; the CPMC institutional review board approved the study. All patients seropositive for hepatitis B surface antigen (HBsAg) and hepatitis B core antibody (anti-HBc) immunoglobulin $\mathrm{G}(\mathrm{IgG})$ for at least 6 months were included. 
Patient demographics (age, sex, country of origin, ethnicity, race, mode of transmission, and family history) were obtained through patient interviews, paper charts, and the clinics' and hospitals' electronic database; laboratory data were derived from the database.

\section{Laboratory analysis}

Serologic, mutation, and biochemical tests were performed at baseline at the time of first consultation (Table 1); no patients were tested thereafter for mutations. The limit of detection of HBV DNA quantification is $100 \mathrm{IU} / \mathrm{ml}$. The INNO-LiPA assay had been performed to identify nucleotide polymorphisms at nt1762 and nt1764 in the basal CP region and at codon 28 in the PC region, down to the $4 \%$ level.

\section{Statistical analysis}

Relationships between categorical variables were analyzed with Pearson's chi-square test; Fisher's exact test was used in cases where an expected cell count was below 5. Continuous outcomes were analyzed with Welch's $t$ test. Because of the censored nature of HBV DNA quantity, we report significant differences among groups based on a parametric survival model, assuming that the $\log _{10}$ of $\mathrm{HBV}$ DNA quantity is normally distributed. Logistic regression was used to relate continuous and categorical covariates to binary outcomes. With all analyses, a $p$ value below 0.05 was considered to indicate a statistically significant result.

\section{Results}

At the time of presentation to the clinic, $39 \%(n=459)$ of patients were nucleos(t)ide analogue treatment-naïve. Table 2 outlines the details of treatment history at or before the time of analysis. The patient population consisted of $64.7 \%$ males. Mean age at the time of presentation was 49.7 (range $15-88$ years). Asians $(n=684,57.7 \%)$ and Caucasians $(n=361,30 \%)$ were the dominant races. Non-Hispanic whites $(n=322,27 \%)$ and Chinese $(n=216,18 \%)$ constituted the major ethnic groups. Most patients were identified as infected only with HBV (HBVmonoinfected; no coinfection with HIV, HCV, and/or HDV). However, coinfection status was not known in all patients: of 816 patients with known status, $5.4 \%$ were HIV-infected; of 880 with known status, $9.5 \%$ were HCVinfected; of 410 with known status, $2.9 \%$ were HDVinfected. Complete demographics are outlined in Table 3. The mean MELD score in patients with known cirrhosis was 11.5 (range 6-40) at the time of initial presentation, and $115(9.7 \%)$ patients had received a liver transplant at
Table 1 Laboratory test with their respective methods used

\begin{tabular}{ll}
\hline Laboratory test & Methodology used \\
\hline HCV, HDV, HIV & Immunoassays \\
ALT, AST, bilirubin & Spectrophotometry \\
INR & Photo-optical clot detection \\
AFP & Liquid-phase binding assay system \\
Hepatitis B serologies & Immunoassays \\
HBV genotype & Genotype specific primers or use of the \\
& line probe assay (INNO-LiPA assay v3, \\
HBV DNA & Innogenetics NV, Gent, Belgium) \\
quantification & Roche real time Taqman PCR assay \\
PC and BCP & INNO-LiPA assay \\
\hline
\end{tabular}

$H C V$ hepatitis $\mathrm{C}$ virus, $H D V$ hepatitis delta virus, $H I V$ human immunodeficiency virus, $H B s A g \mathrm{HBe}$ antigen, anti-HBe antigen, INR international normalized ratio, $A F P$ alpha fetoprotein

Table 2 Treatment history of the study population

\begin{tabular}{lcc}
\hline Parameter & $\begin{array}{c}\text { Patients } \\
(n)\end{array}$ & $\begin{array}{l}\text { Percent of } \\
\text { patients }(\%)\end{array}$ \\
\hline Treatment-naive & 459 & 38.70 \\
History of treatment with only a single agent & \\
Lamivudine & 102 & 8.60 \\
Adefovir & 20 & 1.69 \\
Entecavir & 161 & 13.58 \\
Tenofovir & 6 & 0.51 \\
Telbivudine & 1 & 0.08 \\
History of treatment with more than one agent & \\
Lamivudine and adefovir & 6 & 0.51 \\
Lamivudine and entecavir & 7 & 0.59 \\
Lamivudine and tenofovir & 14 & 1.18 \\
Entecavir and adefovir & 6 & 0.51 \\
Entecavir and tenofovir & 1 & 0.08 \\
Lamivudine, adefovir and entecavir & 3 & 0.25 \\
Unknown & 400 & 33.73 \\
\hline
\end{tabular}

${ }^{a}$ Treatment with these agents either sequentially or in combination

the time of their blood sampling. In the 423 patients (35.6\%) with genotype testing, the predominant genotypes were C $(30.5 \%)$, A (23.4\%), B (21.5\%) and D (7.8 \%); the mutational profile is shown in Table 4. There was a significant difference between genotypes in the prevalence of any mutation versus none $(p=0.0426)$.

Prevalence of mutations

Of the total population $(n=1,186), 926$ patients were tested for HBeAg status. Of the patients tested, $37 \%$ $(n=344)$ were $\mathrm{HBeAg}$-positive and $63 \%(n=582)$ were HBeAg-negative. The INNO-LiPA test to check for PC and 
Table 3 Demographic characteristics of patients infected with chronic hepatitis $\mathrm{B}, N=1,186$

\begin{tabular}{|c|c|}
\hline Characteristic & Value \\
\hline \multicolumn{2}{|l|}{ Age } \\
\hline Mean (SD) & $49.74(13.54)$ \\
\hline \multicolumn{2}{|l|}{ Sex } \\
\hline Female & $414(34.91 \%)$ \\
\hline Male & $767(64.67 \%)$ \\
\hline Missing & $5(0.42 \%)$ \\
\hline \multicolumn{2}{|l|}{ FH of HCC } \\
\hline Neg & $792(66.78 \%)$ \\
\hline Pos & $99(8.35 \%)$ \\
\hline Missing & $295(24.87 \%)$ \\
\hline \multicolumn{2}{|l|}{ Race } \\
\hline Asian & $684(57.67 \%)$ \\
\hline Caucasian & $361(30.44 \%)$ \\
\hline Missing & $91(7.67 \%)$ \\
\hline Black & $25(2.11 \%)$ \\
\hline Indian subcont. & $13(1.10 \%)$ \\
\hline Mideastern & $6(0.51 \%)$ \\
\hline Pacific Island & $4(0.34 \%)$ \\
\hline Hispanic & $2(0.17 \%)$ \\
\hline \multicolumn{2}{|l|}{ Mode of transmission } \\
\hline Vertical/childhood & $621(52.36 \%)$ \\
\hline Missing & $363(30.61 \%)$ \\
\hline Sexual & $88(7.42 \%)$ \\
\hline IVDU & $37(3.12 \%)$ \\
\hline BT & $27(2.28 \%)$ \\
\hline Needle & $24(2.02 \%)$ \\
\hline Vert/BT & $6(0.51 \%)$ \\
\hline IVDU/sexual & $4(0.34 \%)$ \\
\hline Vert/needle & $2(0.17 \%)$ \\
\hline Sexual/vertical & $2(0.17 \%)$ \\
\hline Needle/BT & $2(0.17 \%)$ \\
\hline IVDU & $2(0.17 \%)$ \\
\hline Homosexual & $2(0.17 \%)$ \\
\hline Travel & $1(0.08 \%)$ \\
\hline Transplant & $1(0.08 \%)$ \\
\hline Needle/sexual & $1(0.08 \%)$ \\
\hline IVDU/homosexual & $1(0.08 \%)$ \\
\hline IVDU/BT & $1(0.08 \%)$ \\
\hline BT/childhood & $1(0.08 \%)$ \\
\hline
\end{tabular}

FH of HCC family history of hepatocellular carcinoma, Neg negative, Pos positive, Indian subcont. Indian sub-continent, Vert vertical, $I V D U$ intravenous drug use, $B T$ blood transfusion

CP mutations was performed in 194 patients; details of prevalence of mutations in $\mathrm{HBeAg}$-positive and $\mathrm{HBeAg}$ negative patients are shown in Fig. 1. In the overall population, the difference in the prevalence of PC mutations, $\mathrm{CP}$ mutations or both in $\mathrm{HBeAg}$-positive patients $(56 \%)$
Table 4 Mutational profile of each HBV genotype

\begin{tabular}{lrlrrr}
\hline $\begin{array}{l}\text { HBV } \\
\text { genotype }\end{array}$ & $\begin{array}{l}\text { No } \\
\text { mutation }\end{array}$ & $\begin{array}{l}\text { CP } \\
\text { only }\end{array}$ & PC only & $\begin{array}{l}\text { PC/CP } \\
\text { mix }\end{array}$ & $\begin{array}{l}\text { Any } \\
\text { mutation }\end{array}$ \\
\hline A & $13(43 \%)$ & $3(10 \%)$ & $10(33 \%)$ & $4(13 \%)$ & $17(57 \%)$ \\
B & $8(17 \%)$ & $3(6 \%)$ & $20(43 \%)$ & $16(34 \%)$ & $39(83 \%)$ \\
C & $11(23 \%)$ & $7(14 \%)$ & $25(51 \%)$ & $6(12 \%)$ & $38(78 \%)$ \\
D & $1(11 \%)$ & $0(0 \%)$ & $6(67 \%)$ & $2(22 \%)$ & $8(89 \%)$ \\
\hline
\end{tabular}

There is a significant difference between genotypes in the prevalence of any mutation versus none $(p=0.0426)$. Data is presented as counts (percentages)

and HBeAg-negative patients (89\%) was statistically significant $(p<0.001)$. When considered separately, there was also a significant difference in the prevalence of PC and/or CP mutations between treatment-naïve HBeAgpositive and $\mathrm{HBeAg}$-negative patients $(n=103$ and $83 \%$ had PC and/or CP mutations; $p<0.001$ ), although not in the treatment-experienced ( $n=72,77 \%$ PC and/or CP mutations; $p=0.193$ ). There was no statistically significant difference in the distribution of the confounding variables of race, gender, or presence of coinfection with HIV, HCV, or HDV in patients with or without these mutations. However, older age was associated with a higher prevalence of PC mutations $(p=0.013)$ in the whole population. The difference in the prevalence of $\mathrm{PC}$ mutations in $\mathrm{HBeAg}$-negative and $\mathrm{HBeAg}$-positive patients was statistically significant when considering the whole sample $(p<0.001)$ and after controlling for age in a logistic regression done on the entire sample $(p<0.001)$ and the treatment-naïve subpopulation $(p<0.001)$, but not in the treatment-experienced or monoinfected subpopulations.

\section{ALT levels with and without mutations}

The mean $\log _{10}$ ALT for the whole population was 1.68 (range 0.47-3.64) as determined at the time of first consultation. There was a significant difference in the mean $\log _{10}$ ALT of patients with both PC and CP mutations $(1.56, \mathrm{SD}=0.30)$ when compared to the whole population of patients without these mutations $(1.76, \mathrm{SD}=0.35$, $p=0.011$ ) (Fig. 2). We found no significant differences in mean $\log _{10}$ ALT when focusing on the treatmentexperienced and monoinfected population. However, in the treatment-naïve group, we found a significant difference between patients with both PC and CP mutations $(1.54, \mathrm{SD}=0.29)$ when compared to patients with no mutation $(1.78, \mathrm{SD}=0.34, p=0.41)$. When controlled for genotype in a linear model, we did not find a significant difference in $\log _{10}$ ALT between any mutation groups. 
Fig. 1 Distribution of PC and/ or $\mathrm{CP}$ mutations with respect to $\mathrm{HBe} A$ g-positive and $\mathrm{HBeAg}-$ negative patients. $\mathrm{HBeAg}+v e$ $\mathrm{HBe}$ g positive, $\mathrm{HBeAg}-v e$ HbeAg negative, $P C$ precore mutations only, $C P$ core promoter mutations only, $P C / C P$ both precore and core promoter mutations

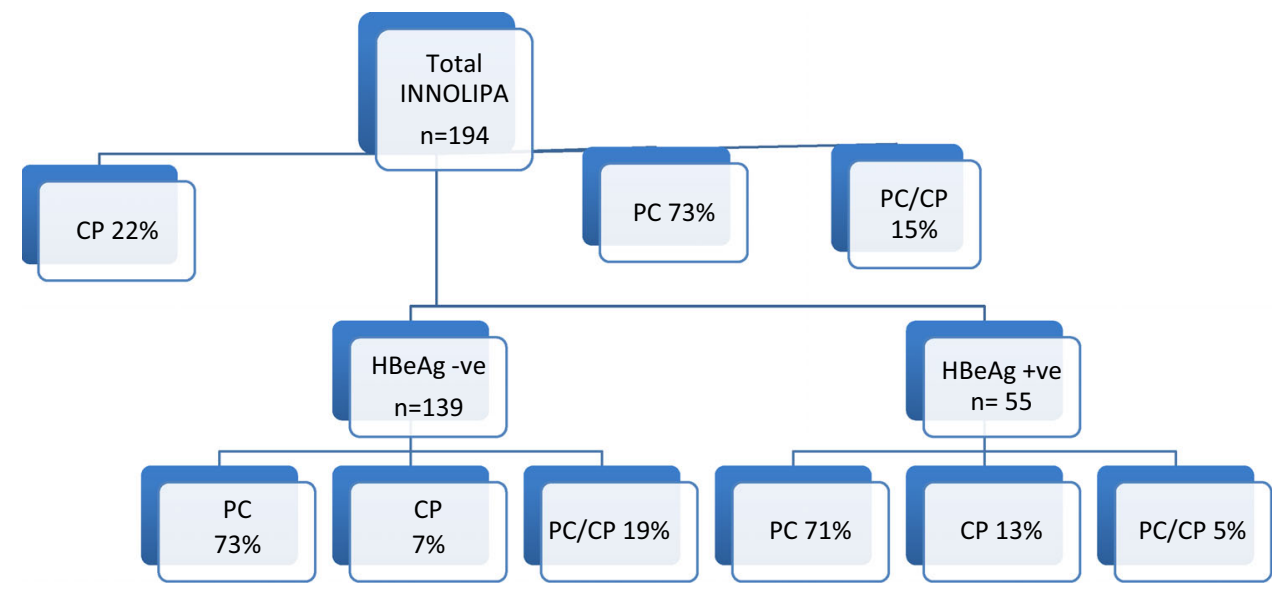

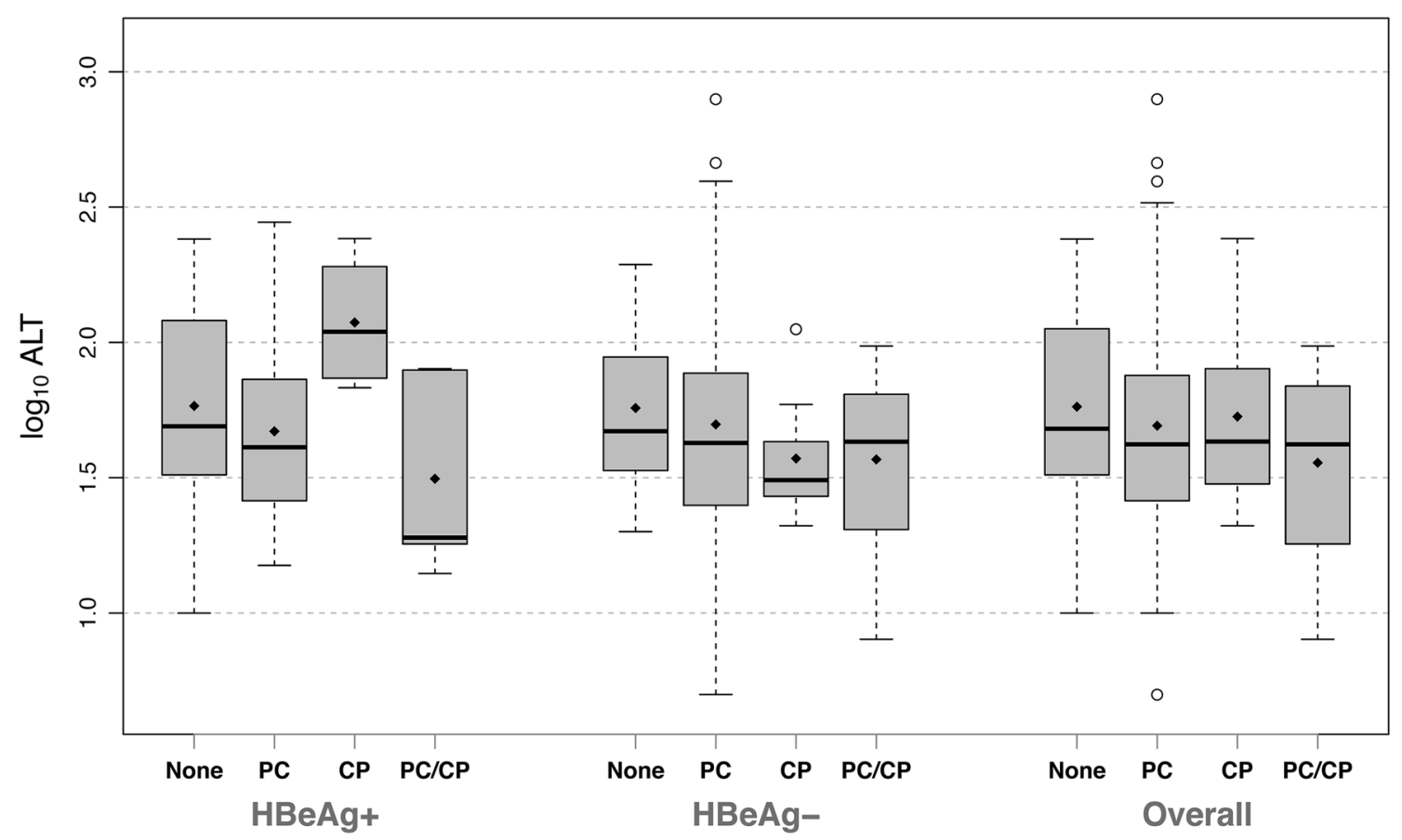

Fig. 2 ALT levels relative to precore and core promoter mutations. The diamonds in each boxplot represent the mean for that group, while the solid line represents the median. Outliers are defined as being beyond 1.5 times the interquartile range (IQR) from the median,

\section{Association of various ALT levels with liver disease}

To see the association of various levels of ALT with cirrhosis and HCC, the study population was divided into four sub-groups according to the ALT level at the first time of diagnosis. As shown in Table 5, these included patients with ALT level $\leq 0.5 \times \mathrm{ULN}$ (group 1), $0.5-1 \times \mathrm{ULN}$ (group 2), 1-2 $\times$ ULN (group 3) and $>2 \times \mathrm{ULN}$ (group 4). Our analysis showed significantly higher incidence of and are represented by empty circles. $P C$ precore mutations only, $C P$ core promoter mutations only, $P C-C P$ both precore and core promoter mutations, $\mathrm{HBeAg}+$ hepatitis $\mathrm{B}$ e antigen positive, $\mathrm{HBeAg}-$ hepatitis $B$ e antigen negative

cirrhosis in group 3 (OR 3.514, $p=0.013$ ) and group 4 (OR 2.994, $p=0.031$ ) when compared to group 1 . We did not find a significant difference between any ALT groups in the treatment-experienced and monoinfected subpopulations. However, we did find a significant difference between group 4 and group 1 in the treatment-naïve group (OR 8.110, $p=0.0491$ ). When controlling for HBV genotype in a logistic regression model, we did not find a significant difference in the incidence of cirrhosis between 
Table 5 Prevalence of hepatocellular carcinoma (HCC) and cirrhosis according to ALT level

\begin{tabular}{|c|c|c|c|c|}
\hline \multirow[t]{2}{*}{ ALT group (range) } & \multicolumn{2}{|l|}{$\mathrm{HCC}$} & \multicolumn{2}{|l|}{ Cirrhosis } \\
\hline & Patients (\%) & $p$ value & Patients (\%) & $p$ value \\
\hline Group $1(0-14)$ & 5.6 & _- & 16.7 & - \\
\hline Group 2 (15-29) & 8.6 & 0.460 & 28.6 & 0.182 \\
\hline Group $3(30-59)$ & 14.7 & 0.081 & 41.3 & $0.013 *$ \\
\hline Group $4(\geq 60)$ & 15.1 & 0.071 & 37.5 & $0.031 *$ \\
\hline
\end{tabular}

The $p$ values correspond to a logistic regression with group 1 treated as the reference group

* Statistically significant

any ALT groups. We also found a mathematical increase in the incidence of HCC with the increase in ALT level (5.6\% in group $1,8.6 \%$ in group $2,14.7 \%$ in group 3 and $15.1 \%$ in group 4 ) although these increases were not found to be statistically significant when compared to group 1 (Table 5). We did not find any significant differences in the incidence of HCC across ALT groups when controlling for HBV genotype or within the treatment-naïve, treatmentexperienced, and monoinfected subgroups.

\section{Effect of mutations on HBV viral load}

The HBV DNA levels were measured at the time of INNOLiPA testing in those patients who had INNO-LiPA testing; the DNA levels stated were at the time of first consultation if the INNO-LiPA test was not performed. The effect of various mutations on the $\log _{10}$ HBV DNA was evaluated. The mean $\log _{10}$ HBV DNA of patients without any mutations was $5.71(\mathrm{SD}=2.28)$. In the overall population, when compared with patients without mutations, the mean $\log _{10}$ HBV DNA was significantly lower in patients with PC mutations only (4.82; $\mathrm{SD}=1.98, p=0.019)$ (Fig. 3); those with $\mathrm{CP}$ mutations only $(5.82, \mathrm{SD}=1.20)$ and patients with both $\mathrm{PC}$ and $\mathrm{CP}$ mutations (4.58; $\mathrm{SD}=1.37$ ) were not found to have significantly different mean $\log _{10}$ HBV DNA ( $p=0.895$ and $p=0.074$, respectively). PC mutation only was also found to be significantly associated with lower HBV DNA in a survival regression model controlled for age $(p=0.029)$. In separate analyses, no significant differences were found in $\log _{10}$ HBV DNA across mutations in patients infected only with HBV (excluding patients coinfected with HIV, HCV, or HDV) or in treatment-experienced patients. However, in the treatment-naïve group, we found a significant difference between patients with PC mutations only (4.65, $\mathrm{SD}=1.77, p<0.001)$ and those with both $\mathrm{PC}$ and $\mathrm{CP}$ mutations $(3.87, \mathrm{SD}=1.39, p<0.001)$ when compared to subjects without any mutations $(6.18, \mathrm{SD}=1.90)$.

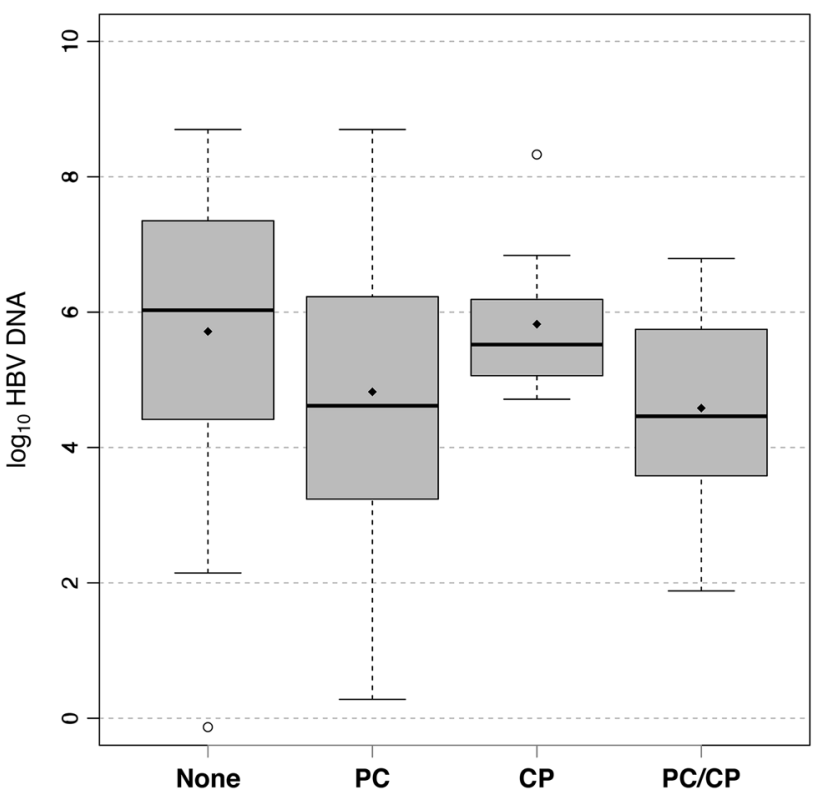

Fig. 3 Effect of mutations on HBV viral levels. For the sake of visualization, right-censored values are left at their lower limit. The diamonds in each boxplot represent the mean for that group, while the solid line represents the median. Outliers are defined as being beyond 1.5 times the interquartile range (IQR) from the median, and are represented by empty circles. $P C$ precore mutations only, $C P$ core promoter mutations only, $P C-C P$ both precore and core promoter mutations

Incidence of cirrhosis

The incidence of cirrhosis (histological or clinical) was also evaluated in the study population. We found that $37 \%$ (268 patients) of the 718 CHB patients who were tested had cirrhosis, with the incidence similar in $\mathrm{HBeAg}$-positive and HBeAg-negative populations (32\% and $37 \%$, respectively). Univariate analysis for the incidence of cirrhosis showed older age $(p<0.001)$, male sex $(p<0.001)$, Caucasian race $(p<0.001)$, presence of HDV antibody $(p<0.001)$, presence of HCV antibody $(p=0.005)$, and PC only mutation ( $p=0.028)$ to be associated with higher incidence of cirrhosis (Fig. 4); there was a lower rate of cirrhosis in patients with genotype $\mathrm{B}$ and $\mathrm{C}$ relative to patients with genotype A $(p=0.002$ and $p=0.007$, respectively). Those covariates whose $p$ values were below 0.05 were included in a multiple logistic regression. However, the multiple logistic regression model did not confirm any covariates to be associated with cirrhosis. We also included both genotype and mutation in a separate multivariate model, and confirmed the higher rate of cirrhosis in subjects with PC mutations when compared to subjects with no mutation when controlled for variations across HBV genotype ( $p=0.020$, OR 5.435). When testing for an interaction between any of the above covariates and treatment history, we only find a significant difference 


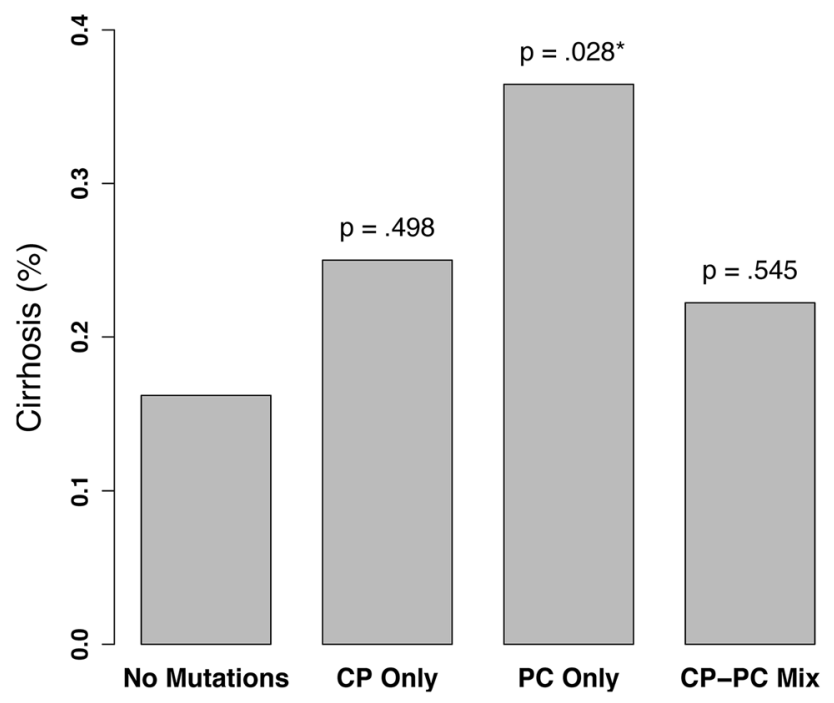

Fig. 4 Effect of mutations on incidence of cirrhosis. Each $p$ value represents the comparison of that group with the no mutations group, computed from a logistic regression. $P C$ precore mutations only, $C P$ core promoter mutations only, $P C-C P$ both precore and core promoter mutations

in the effect of age between treatment-naïve and -experienced patients, with the odds of cirrhosis increasing at a slower rate as a function of age in the treatment-naive group $(p=0.0298)$. We do not find any significant differences between covariates effects between monoinfected and coinfected patients.

\section{Incidence of hepatocellular carcinoma}

There were 129 patients found to have HCC in our study population. The mean alpha-fetoprotein (AFP) was 1,737 (range 1.1-53,727) in patients with HCC. Similarly to another recent study [21], we found a significantly higher incidence of $\mathrm{HCC}$ in patients with $\mathrm{HBeAg}$-negative disease $(n=84,15 \%)$ as compared to patients with HBeAgpositive status $(n=19,6 \%, p<0.001)$. We also found a significantly higher incidence of $\mathrm{HCC}$ in $\mathrm{HBeAg}$-negative patients as compared to $\mathrm{HBeAg}$-positive in both the treatment-naïve and -experienced groups (13 vs. $4 \%$, $p=0.020$ and 21 vs. $9 \%, p=0.007$, respectively), but not in the HBV-monoinfected group (6 vs. $4 \%, p=0.75$ ). A total of 16 patients with HCC underwent INNOLiPA testing; of these, ten tested positive for PC mutation only, two tested positive for both PC and CP mutations, and four tested negative for both PC and $\mathrm{CP}$ mutations. There were no significant differences in the incidence of $\mathrm{HCC}$ in relation to the presence of $\mathrm{CP}$ only, $\mathrm{PC}$ only, or both $\mathrm{PC}$ and $\mathrm{CP}$ mutations when looking at the entire study population, treatment-experienced patients, treatment-naïve patients, or monoinfected patients (excluding coinfected patients), nor was there a significant difference in the distribution of HBV genotype in patients with and without HCC in any of these subgroups.

\section{Discussion}

We confirmed the occurrence of CP and/or PC mutations in the viral populations of a substantial percentage of $\mathrm{HBeAg}+$ patients. In previous US studies, the incidence of $\mathrm{PC}$ mutations (only) in $\mathrm{HBeAg}$-positive patients has been reported as ranging from $9 \%$ [4] to $28 \%$ [5], while in our population, of the $55 \mathrm{HBeAg}$-positive patients who underwent iNNOLipa testing, the incidence was $71 \%$. In our study, in the whole population of patients who underwent iNNOLipa testing $(n=194)$, the overall prevalence of PC mutations was $73 \%$. The much lower overall $27 \%$ PC prevalence reported by Chu et al. [4] may be explained by the selection bias of only including treatment-naïve patients while our study drew from what may be a much more representative community population that included both treatment-experienced and -naïve patients.

The $13 \%$ incidence of $\mathrm{CP}$ mutations in our $\mathrm{HBeAg}$ positive patient population is lower compared to previous US studies which have reported a range from $28 \%$ [5] to $36 \%$ [4]. We found a higher prevalence (9\%) of HBeAgpositive patients harboring both $\mathrm{PC}$ and $\mathrm{CP}$ mutations compared to the prevalence of $4 \%$ [4] previously reported. In genotypes $\mathrm{B}$ and $\mathrm{C}$, the previously reported prevalence of PC mutations was 34 and $7 \%$, respectively [5], substantially lower than the prevalence we found in these genotypes (B, $43 \%$ and $\mathrm{C}, 51 \%$ ). We found higher prevalence of PC mutations with older age, in contrast to Vutien et al. [5] who reported higher prevalence of $\mathrm{CP}$ mutations with age $>40$ years, a finding that may be partially explained by a possible selection bias created by their inclusion of almost entirely only Asian American patients with genotypes B and C.

We also found a statistically significant difference in the prevalence of PC mutations only in $\mathrm{HBeAg}$-negative and HBeAg-positive patients when considering the whole sample and the treatment-naïve subpopulation. We did not find the association between the prevalence of these variants and ethnicity and place of birth previously reported in a study of treatment-naïve patients from tertiary care centers [4], possibly due to a change in the prevalence of these mutations as the $\mathrm{CHB}$ population ages and the virus undergoes mutations with longer duration of disease. In addition, our population consisted of an equal proportion of treatment-naïve and -experienced patients from all ethnic backgrounds and from both tertiary care centers and community clinics and thus may be more representative of the prevalence of $\mathrm{HBV}$ variants in the United States. 
In previous studies there have been varying reports on the association of mutations with the severity of liver disease. We found a higher rate of cirrhosis in patients with only PC mutations when compared to patients with no mutations when controlled for variations across $\mathrm{HBV}$ genotypes. Chu et al. [4] reported that patients with $\mathrm{CP}$ mutations with or without PC mutations were more likely to have decompensated cirrhosis. Since the lower number of patients in some of our sub-populations may have influenced these results, further research will be needed to elaborate on these findings. The association of PC and CP mutations with HBV viral load has also been unclear in both $\mathrm{HBeAg-negative} \mathrm{and} \mathrm{-positive} \mathrm{patients.} \mathrm{In} \mathrm{our} \mathrm{study}$ we found significantly lower levels of HBV DNA in patients with $\mathrm{PC}$ mutations only in comparison to patients with no mutations in both a univariate survival regression model (mutation only) and in a model controlled for age. We found significantly lower levels of DNA in patients with only PC mutations and patients with both PC and $\mathrm{CP}$ mutations in the treatment-naïve population, a difference that was not observed in treatment-experienced patients.

Multiple studies have reported an association between CP mutations and an increased risk of $\operatorname{HCC}[9,10,12,22]$. A study by Yang et al. [13] found this association, combined with an apparent protective effect of PC mutation, with a hazard ratio of developing $\mathrm{HCC}$ of 0.34 for precore G1896A versus wild type. In our study, there were no significant differences in the incidence of $\mathrm{HCC}$ in relation to the presence of PC only or CP only mutations, or the combination of both PC and CP mutations. Although we did not find a clear association of PC mutations with either the development of or protection against HCC, it is important to recognize the limits of this study design. In addition, there continues to be a controversy about whether $\mathrm{CP}$ and $\mathrm{PC}$ mutations are dominant factors in the development of HCC. The presence of these mutations may be confounded by age, genotype, and other variables. Ultimately, the best approach to taking the presence of these mutations into account in terms of predicting $\mathrm{HCC}$ risk may be to place them in the type of scoring system proposed by UCLA researchers in which CP mutation is only one of multiple factors previously identified as independent risk factors which are assigned numerical scores that are weighted based on expert opinion in order to yield a risk impact score that may be used to make treatment decisions [23, 24].

Higher levels of ALT have been associated with advanced liver fibrosis or cirrhosis, and have served as a predictor for the development of complications of $\mathrm{CHB}$. Kim et al. [25] reported that there is a positive association between serum aminotransferase concentration, even when it is within the current normal range (35-40 IU/1), and mortality from liver disease. A study by Yuen et al. [26] showed that ALT levels of 0.5-2 $\times$ ULN (ULN: $53 \mathrm{U} / 1$ for males and $31 \mathrm{U} / 1$ for females) are associated with an increased risk of developing complications (including ascites, esophageal varices, encephalopathy and HCC) compared with patients with ALT levels $<0.5 \times$ ULN. In our study, with the upper limit of normal defined as 30 for both males and females, patients with ALT 0.5-1 $\times$ ULN were not found to be at increased risk of developing cirrhosis or HCC as compared to patients with ALT $<0.5 \times$ ULN. However, we found a significantly higher incidence of cirrhosis in patients with ALT level $1-2 \times \operatorname{ULN}(\mathrm{OR} 3.514, p=0.013)$ and patients with ALT level $>2 \times \mathrm{ULN}$ (OR 2.994, $p=0.031$ ). If confirmed, this observation could put in question the guidelines made by liver societies worldwide in which treatment is only recommended with ALT $>2 \times$ ULN.

Our findings of the presence of significantly $\operatorname{lower} \log _{10}$ ALT levels in association with patients who have both PC and CP mutations may serve as a basis for further studies to evaluate the duration of treatment of such patients. This could be an important observation, especially in regard to treatment duration of patients with $\mathrm{HBeAg}$-positive and -negative disease. The exact mechanism of this difference is not entirely clear but the likely explanation could be that our patient population included both treatment-naïve patients and those who had been treated with nucleos(t)ide analogues. This may show that development of combined $\mathrm{PC}$ and $\mathrm{CP}$ mutations, whether in the natural history of $\mathrm{CHB}$ or during antiviral treatment, carries a better prognosis. A limitation of our study is that, given the fluctuating nature of $\mathrm{CHB}$, a cross-sectional approach may over- or underestimate the conclusions drawn. Thus, a longitudinal study will be needed to confirm our findings.

Treatment guidelines from such major liver societies as the American Association for the Study of Liver Diseases (AASLD), the European Association for the Study of the Liver (EASL) and the Asian Pacific Association for the Study of the Liver (APASL) take into account ALT levels as one of the indicators to start therapy [27-29]. According to these guidelines, both $\mathrm{HBeAg}$-positive and -negative patients with $\mathrm{ALT} \leq 2 \times \mathrm{ULN}$ can be observed without treatment. Our study showed an increased incidence of cirrhosis in patients with ALT level $>1 \times$ ULN. Further studies are needed to clarify the ALT level that should be used as an indicator for beginning therapy.

In addition, one of the criteria for stopping treatment is based on $\mathrm{HBeAg}$ seroconversion in $\mathrm{HBeAg}$-positive CHB. The criteria for stopping treatment are unclear in $\mathrm{HBeAg}$ negative CHB. And this raises a major question: when to stop therapy in a patient with $\mathrm{HBeAg}+$ disease who also harbors both PC and CP mutations. Some patients are committed to therapy with antivirals for life if they are not able to attain the predefined end points such as sustained virologic response (undetectable HBV DNA) and 
biochemical response (normal ALT). The longer duration of treatment with antiviral agents puts patients at risk for the development of resistant HBV and medication-related side effects. In our study, we showed that PC and CP mutations may be associated with milder liver disease in some patients, with lower ALT levels in those with both PC and CP mutations, and lower HBV DNA levels in those with PC mutations only. Our cross-sectional study may serve as a basis for longitudinal studies, which could elucidate this observation and help delineate treatment need and duration in patients with these HBV variants.

Acknowledgements The project described was partially supported by the National Institutes of Health, Grant UL1TR000100. The content is solely the responsibility of the authors and does not necessarily represent the official views of the NIH. The authors would like to express their gratitude to Dr. Lark Lands for her invaluable assistance in preparing the manuscript for publication.

Compliance with ethical requirements and Conflict of interest All procedures followed were in accordance with the ethical standards of the responsible committee on human experimentation (institutional and national) and with the Helsinki Declaration of 1975, as revised in 2008 (5). Informed consent was obtained from all patients for being included in the study. Sumbella F. Baqai, James Proudfoot, Debbie Hana Yi, Michael Mangahas, and Robert G. Gish declare that they have no conflict of interest.

Open Access This article is distributed under the terms of the Creative Commons Attribution License which permits any use, distribution, and reproduction in any medium, provided the original author(s) and the source are credited.

\section{References}

1. Funk ML, Rosenberg DM, Lok AS. World-wide epidemiology of HBeAg-negative chronic hepatitis B and associated precore and core promoter variants. J Viral Hepat. 2002;9:52-61

2. Takahashi K, Aoyama K, Ohno N, et al. The precore/core promoter mutant (T1762A1764) of hepatitis B virus: clinical significance and an easy method for detection. J Gen Virol. 1995;76(Pt 12):3159-3164

3. Chotiyaputta W, Lok AS. Hepatitis B virus variants. Nat Rev Gastroenterol Hepatol. 2009;6:453-462

4. Chu CJ, Keeffe EB, Han SH, et al. Prevalence of HBV precore/ core promoter variants in the United States. Hepatology. 2003;38:619-628

5. Vutien P, Trinh HN, Nguyen K, et al. Precore and basal core promoter mutations in Asian American patients with hepatitis B e antigen-positive chronic hepatitis B. Aliment Pharmacol Ther. 2013;37:464-472

6. Lindh M, Hannoun C, Dhillon AP, et al. Core promoter mutations and genotypes in relation to viral replication and liver damage in East Asian hepatitis B virus carriers. J Infect Dis. 1999; 179:775-782

7. Yuen MF, Tanaka Y, Ng IO, et al. Hepatic necroinflammation and fibrosis in patients with genotypes $\mathrm{Ba}$ and $\mathrm{C}$, core-promoter and precore mutations. J Viral Hepat. 2005;12:513-518

8. Lin CL, Liao LY, Wang CS, et al. Basal core-promoter mutant of hepatitis B virus and progression of liver disease in hepatitis B e antigen-negative chronic hepatitis B. Liver Int. 2005;25:564-570
9. Baptista M, Kramvis A, Kew MC. High prevalence of 1762(T) 1764(A) mutations in the basic core promoter of hepatitis B virus isolated from black Africans with hepatocellular carcinoma compared with asymptomatic carriers. Hepatology. 1999;29:946-953

10. Fang ZL, Ling R, Wang SS, et al. HBV core promoter mutations prevail in patients with hepatocellular carcinoma from Guangxi, China. J Med Virol. 1998;56:18-24

11. Kao JH, Chen PJ, Lai MY, et al. Basal core promoter mutations of hepatitis B virus increase the risk of hepatocellular carcinoma in hepatitis B carriers. Gastroenterology. 2003;124:327-334

12. Yuen MF, Tanaka Y, Shinkai N, et al. Risk for hepatocellular carcinoma with respect to hepatitis B virus genotypes B/C, specific mutations of enhancer II/core promoter/precore regions and HBV DNA levels. Gut. 2008;57:98-102

13. Yang HI, Yeh SH, Chen PJ, et al. Associations between hepatitis $\mathrm{B}$ virus genotype and mutants and the risk of hepatocellular carcinoma. J Natl Cancer Inst. 2008;100:1134-1143

14. Carman WF, Fagan EA, Hadziyannis S, et al. Association of a precore genomic variant of hepatitis B virus with fulminant hepatitis. Hepatology. 1991;14:219-222

15. Liang TJ, Hasegawa K, Rimon N, et al. A hepatitis B virus mutant associated with an epidemic of fulminant hepatitis. N Engl J Med. 1991;324:1705-1709

16. Liu CJ, Kao JH, Lai MY, et al. Precore/core promoter mutations and genotypes of hepatitis B virus in chronic hepatitis B patients with fulminant or subfulminant hepatitis. J Med Virol. 2004;72:545-550

17. Yoo BC, Park JW, Kim HJ, et al. Precore and core promoter mutations of hepatitis B virus and hepatitis B e antigen-negative chronic hepatitis B in Korea. J Hepatol. 2003;38:98-103

18. Chen WN, Oon CJ. Mutations and deletions in core promoter and precore stop codon in relation to viral replication and liver damage in Singaporean hepatitis B virus carriers. Eur J Clin Invest. 2000;30:787-792

19. Jammeh S, Tavner F, Watson R, et al. Effect of basal core promoter and pre-core mutations on hepatitis B virus replication. J Gen Virol. 2008;89:901-909

20. Ghabeshi S, Sharifi Z, Hosseini SM, et al. Correlation between viral load of HBV in chronic hepatitis B patients and precore and basal core promoter mutations. Hepat Mon. 2013;13:e7415

21. Khan A, Al Balwi MA, Tanaka Y, et al. Novel point mutations and mutational complexes in the enhancer II, core promoter and precore regions of hepatitis B virus genotype D1 associated with hepatocellular carcinoma in Saudi Arabia. Int J Cancer. 2013;133:2864-2871

22. Zhong S, Chan JY, Yeo W, et al. Frequent integration of precore/ core mutants of hepatitis B virus in human hepatocellular carcinoma tissues. J Viral Hepat. 2000;7:115-123

23. Han SH, Durazo FA, Saab S, et al. A proposed, evidence-based approach to the treatment of chronic Hepatitis B. J Clin Gastroenterol. 2011;45:259-266

24. Tong MJ, Pan CQ, Hann HW, et al. The management of chronic hepatitis B in Asian Americans. Dig Dis Sci. 2011;56:3143-3162

25. Kim HC, Nam CM, Jee SH, et al. Normal serum aminotransferase concentration and risk of mortality from liver diseases: prospective cohort study. BMJ. 2004;328:983

26. Yuen MF, Yuan HJ, Wong DK, et al. Prognostic determinants for chronic hepatitis B in Asians: therapeutic implications. Gut. 2005;54:1610-1614

27. Lok AS, McMahon BJ. AASLD practice guidelines. Chronic hepatitis B: update 2009. Hepatology. 2009;50:1-36

28. European Association for the Study of the Liver. EASL clinical practice guidelines: management of chronic hepatitis B. J Hepatol. 2009;50:227-242

29. Liaw YF, Leung N, Kao JH, et al. Asian-Pacific consensus statement on the management of chronic hepatitis B: a 2008 update. Hepatol Int. 2008;2:263-283 